\title{
Traumatic asphyxia in the young
}

\author{
Roger W. Byard ${ }^{1}$
}

Received: 26 March 2015 / Accepted: 22 June 2015 / Published online: 8 July 2015

(C) Springer-Verlag Berlin Heidelberg 2015

The recent report by Cortis et al. provides a comprehensive overview of traumatic/crush asphyxia as well as drawing attention to potential dangers to young children from automatic revolving doors [1]. The authors demonstrate the key role that forensic pathology can play in identifying dangerous situations and devices, and in disseminating this information to the wider professional community [2]. Young children are at increased risk of traumatic asphyxia in addition to other more common accidents such as drowning, as they often fail to appreciate possible dangers, and when confronted by a potentially lethal situation are unable to self-extricate. The latter may be simply due to poor muscle development, or to a lack of understanding of how disentangle or remove themselves from a particular place $[2,3]$.

It is well recognized that there are no pathognomonic markers for asphyxia, although victims of traumatic asphyxia usually have patterned markings on the torso, intense engorgement of the face and neck with petechial hemorrhages, subconjunctival hemorrhages, and bleeding from the nose and ears. One feature that has recently been noted involves scattered blood lakes or islands within the colloid of the thyroid gland [4]. These apparently arise from rupture of intensely congested stromal capillaries into the adjacent follicles. As the sensitivity and specificity of this finding in traumatic asphyxia is currently unclear, it would be of interest to know whether this feature was present in the reported case.

\section{References}

1. Cortis J, Falk J, Rothschild MA. Traumatic asphyxia - fatal accident in an automatic revolving door. Int J Leg Med doi:10.1007/s00414015-1169-3.

2. Byard RW (2000) Accidental childhood death and the role of the pathologist. Pediatr Dev Pathol 3:405-418

3. Byard RW, Hanson KA, James RA (2003) Fatal unintentional traumatic asphyxia in childhood. J Paediatr Child Health 39:31-32

4. Byard RW (2013) Pathological changes in the thyroid gland in crush asphyxia. Forensic Sci Med Pathol 9:568-572
Roger W. Byard

roger.byard@sa.gov.au

1 Discipline of Anatomy and Pathology, Level 3 Medical School North Building, The University of Adelaide, Frome Road,

Adelaide, SA 5005, Australia 